\title{
Not avian but mammalian scavengers efficiently consume carcasses under heavy snowfall conditions: a case from northern Japan
}

\author{
Hiroto Enari ${ }^{1}\left[\right.$ Haruka S. Enari $^{1}$
}

Received: 31 August 2020 / Accepted: 8 December 2020 / Published online: 18 January 2021

(c) The Author(s) 2021

\begin{abstract}
Interest in trophic interactions and ecosystem functions derived from carcass consumption by scavengers has been increasing. Here, we conducted the first evaluation of scavenging processes in an ecosystem with heavy snow, located in northern Japan, which is characterized by the limitations of visual and odor cues to detect carcasses. In this study, we verified the behavioral traits and assemblage compositions of avian and mammalian scavengers, which consumed six different carcass types buried in snow. We measured the visits of scavengers using camera traps between 2010 and 2020. The total scavenger richness observed was relatively low (only 12 species) compared to warmer biomes. We observed seven avian scavenger species, but their visit frequencies were extremely low compared with those of nocturnal mammalian scavengers, such as raccoon dogs (Nyctereutes procyonoides) and martens (Martes melampus), which were able to detect carcasses more rapidly and frequently. Our findings imply that large snow piles significantly prevent avian scavengers from detecting carcasses. In contrast, the snow piles could protect carcasses from the freezing air and ensure the occurrence of a basal level of microbial decomposition, possibly leading to carcass decomposition. This probably results in carcasses still providing odor cues for mammalian scavengers with heightened sense of smell. Moreover, considering the high carcass consumption rate $(91.3 \%$ of full-body carcass; $n=23$ ) and short carcass detection times (approximately $90 \mathrm{~h}$ ) observed, it is possible that scavenging in heavy snowfall conditions has become systematically integrated into the foraging tactics of many mammalian scavengers.
\end{abstract}

Keywords Camera trap $\cdot$ Cannibalism $\cdot$ Odor cue $\cdot$ Scavenging $\cdot$ Visual cue

\section{Introduction}

Carcass consumption by scavengers has become a popular topic for research, in an attempt to better understand not only the function of scavenging in ecosystems, such as accelerating nutrient cycling and modifying disease spreading (Mateo-Tomás et al. 2017), but also an overview of local ecosystem processes (DeVault et al. 2003; Moleón et al. 2014; Sebastián-González et al. 2020). Recent studies have proven the strong influence of food resources available from vertebrate carcasses-i.e., relying not on predation but animal deaths due to malnutrition, disease, exposure, parasites, and accidents—on the foraging behaviors of various

Handling Editor: Adriano Martinoli.

Hiroto Enari

h_enari@hotmail.com

1 Yamagata University, 1-23, Wakabamachi, Tsuruoka, Yamagata 997-8555, Japan carnivores, resulting in changing native trophic networks (DeVault et al. 2003; Selva and Fortuna 2007; Wilson and Wolkovich 2011; Beasley et al. 2015). Moreover, these studies, which have demonstrated trophic interactions via the most common scavengers that seem to only consume carcasses opportunistically (Wilman et al. 2014), could represent a key ecological process, referred to as weak links in the food web, which are important in promoting community stability and persistence (DeVault et al. 2003; Selva et al. 2005; Selva and Fortuna 2007; Beasley et al. 2019). In particular, it is possible that the importance of the weak links further increases under harsh environmental conditions, which could strongly limit food resources and raise the mortality rates of most animals (DeVault et al. 2003; Selva et al. 2005). In fact, the supply of carcasses is more abundant and predictable in colder seasons, and winter carcasses contribute significantly more to the nested structure (or nestedness) of the scavenger community (Selva and Fortuna 2007; Sebastián-González et al. 2020). In contrast, in ecosystems where hibernating mammals serve as dominant scavengers 
and monopolize resources (e.g., black bears, Ursus americanus), the richness of scavenger species tends to increase during winters, while a decrease in the nestedness of their community is often observed (Allen et al. 2014; SebastiánGonzález et al. 2020).

Northern Japan is known worldwide as one of the regions with the heaviest snowfall. Nearly half a year of heavy snowfall results in an increase in the mortality rate of non-hibernating mammals, sometimes causing mass mortality-e.g., Japanese macaque, Macaca fuscata (Koganezawa 1991); Japanese serow, Capricornis crispus (Ochiai et al. 1993); and sika deer, Cervus nippon (Takatsuki et al. 1994). In this manner, carcasses are constantly accumulating and being buried under snow in the winter. There have been some attempts to prove the consumption process of mammalian carcasses in the temperate forests of Japan, which have shown that raccoon dogs (Nyctereutes procyonoides) and Asian black bears (Ursus thibetanus) are the most efficient vertebrate scavengers (Inagaki et al. 2020), whereas invertebrate scavengers, such as burying beetles (Nicrophorus spp.), functionally compensate for this process when vertebrate scavengers are limited (Sugiura and Hayashi 2018). Note that these consumption patterns were observed during non-snowy seasons (i.e., summer or fall). Even if we look into similar studies conducted in other parts of the world, little is known about the ecological influence of this physical process on the native trophic networks under conditions of cold and snow. These networks could be markedly characterized by the heavy reliance on vertebrate scavengers influenced by behavioral suppression associated with severe winter environments (Huggard 1993; Selva et al. 2003, 2005) but hardly at all on invertebrates and microbes, which could promote carcass consumption in warmer seasons, especially under dense vegetation which prevents vertebrates from accessing the carcasses (Smith et al. 2017).

In general, the scavenging efficiency (or carcass consumption rate) by vertebrates varies widely, with estimates ranging between 13 and 100\% (DeVault et al. 2003), and this could be influenced by various factors, including carcass type and conspicuousness, habitat, climate, the composition of resident vertebrate and invertebrate communities (DeVault et al. 2003), anthropic impacts (Sebastián-González et al. 2019), and the biomass and productivity of the regional ecosystem (Sebastián-González et al. 2020). In the case of warmer forests, scavenging efficiency is positively correlated with ambient temperature, as the rise in temperature contributes to increasing the activity of arthropods, bacteria, and fungi, and thus carcasses emit putrefactive odors more rapidly, allowing scavengers to quickly locate them (DeVault and Rhodes 2002; DeVault et al. 2003). Many mammalian scavengers primarily use odor cues to locate carcasses rather than visual cues (DeVault and Rhodes 2002; DeVault et al. 2003). Here, the question arises as to whether carcasses are less efficiently consumed by vertebrate scavengers (both avian and mammalian species) under freezing and heavy snow conditions, which not only deprive them of visual cues but also constrain odor cues by slowing down the decay process and physically masking the odor.

In this context, we conducted the first evaluation of the scavenging process in a heavy snow ecosystem, characterized by the limitations of visual and odor cues. We set the study area in the northernmost mainland of Japan where obligate scavengers, i.e., old world (Aegypiinae and Gypaetinae) and new world vultures (Cathartidae), are originally absent. This area is also known as the northernmost habitat of any nonhuman primate species (i.e., Japanese macaques). The decomposition process of primate carcasses has never been studied to date, with the exception of the golden snubnosed monkey, Rhinopithecus roxellana, during spring (Huang et al. 2014). Using camera traps to detect scavengers consuming carcasses, we verified whether the carcasses buried in snow were accessible and, if so, compared (1) the consumption behaviors of the scavengers, including avian and terrestrial species, and (2) the species richness among scavenger assemblages, using different carcass types.

\section{Materials and methods}

\section{Study area}

We conducted the study experiments at the periphery of UNESCO World Natural Heritage site of Shirakami Mountains, located in northernmost mainland Japan $\left(40^{\circ} 30^{\prime}-40^{\circ} 36^{\prime} \mathrm{N}, 140^{\circ} 12^{\prime}-140^{\circ} 16^{\prime} \mathrm{E}\right)$. In this area, there are typical cool-temperate broadleaved forests (composed of beech, Fagus crenata, and oak, Quercus crispula) and cedar plantations (Cryptomeria japonica). Habitat type, including the extent of human disturbance, is a primary factor in determining the accessibility of carcasses to scavengers, possibly resulting in determining the consumption efficacy of carcasses by scavengers (Selva et al. 2005; Sugiura et al. 2013; Smith et al. 2017; Sebastián-González et al. 2020). Therefore, we conducted each experiment only in a mosaic landscape, mixed with small patches of beech and cedar trees (400-500 $\mathrm{m}$ above sea level).

In this area, freezing winters with heavy snowfall are usually observed from late November to early April, and maximum snow depths can reach $3 \mathrm{~m}$. The mean ambient temperature in the coldest month (i.e., January) is -3.0 and $-4.5{ }^{\circ} \mathrm{C}$ during diurnal and nocturnal periods, respectively. Potential vertebrate scavengers here are falconiformes, corvids, and medium-sized mammal carnivores. The apex predator, i.e., gray wolf (Canisu lupus), became extinct by the beginning of the twentieth century (Tsunoda and Enari 2012); therefore, no leftovers of large-sized carcasses 
via wolf predation are available for scavengers (Wilmers et al. 2003). During winter, the typical top scavenger, the black bear, is in hibernation.

We conducted a prior assessment of mammalian relative abundance in the study area using 24 low-glow infrared camera traps (Model HC500, Reconyx, Wisconsin, U.S.A.) with 1-h capture delays. The monitoring period was between June and October of 2013, and the total sampling effort attained 3208 camera-day. Photos acquired by this assessment showed 267 individuals, from nine middle- to large-sized mammalian species. The relative abundance of the respective carnivores was 0.72 (/100 camera-day) for Asiatic black bears, 0.31 for Japanese badgers (Meles anakuma), and 0.22 for both raccoon dogs and Japanese martens (Martes melampus), which were much less abundant than herbivores and omnivores-e.g., 3.55 for Japanese serows, 2.34 for Japanese macaques, and 0.72 for hares (Lepus brachyurus).

\section{Carcass monitoring}

Here, we used vertebrate carcasses belonging to Japanese macaques (10-12 kg, $n=5$ ), masked palm civets (Paguma larvata) (2-5 kg, $n=9$ ), wild boars (Sus scrofa) (1 kg of fresh meat portions, $n=12)$, Japanese hare ( $2-3 \mathrm{~kg}, n=3)$, domestic chickens (Gallus gallus domesticus) (1 kg of fresh meat portions including internal organs, $n=15)$, and raccoon dogs (2-4 kg, $n=6)$. For carcasses of wild origin, we used roadkill or legally culled animals.

We placed each carcass on the mosaic forests, described above, during midwinter with heavy snowfall from 2010 to 2020. To mask carcasses with snow immediately after the placements, we covered the carcasses with a 30-cm layer of snow in cases where heavy snowfall was not observed at the start of the experiments. To prevent scavengers from learning where the carcasses were set, we changed the locations for each experiment, ensuring that the bait sites were at least $1 \mathrm{~km}$ from each other. To cope with the limited visibility due to heavy snowfall, we monitored the consumption of carcasses with $>2$ camera traps: incandescent flash camera traps (Game Spy D50, Moultrie, Alabama, U.S.A.; 3 continuous shots with 5 min capture delay) during 2010 and infrared (Model HC500, Reconyx; 5 continuous shots with no capture delay) after 2010 — placed several meters from the carcasses, with each camera set at different angles and ground heights (Fig. 1). To prevent scavengers from moving the bait from view, we fixed the carcasses to tree trunks with wire. The wire became essentially invisible with snow accumulation.

We recorded carcass decomposition time as the number of minutes from the initial placement time until complete consumption had occurred. We considered complete carcass consumption to have occurred if only bones and

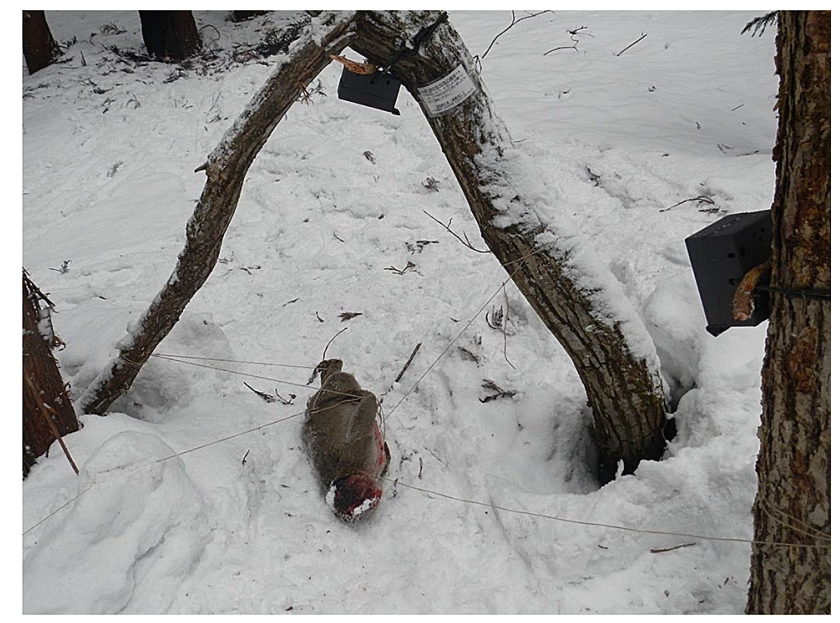

Fig. 1 Setting of carcasses with wires and camera traps in heavy snow areas, northern Japan

skin remained, according to the definition of Moleón et al. (2017).

\section{Data processing}

Based on the photos of scavengers, we calculated the following: (1) day/night-time visit frequency (to maintain data independence, we counted the frequency with respect to each daytime or night-time period by discounting repetitive visits of a species in a single day), (2) time spent feeding per visit (we considered different independent visits when the species returned to carcasses after disappearing in front of cameras for $>1 \mathrm{~h}$ ), (3) initial detection time (time elapsed until the first scavenger species detected each of the carcasses), (4) consumption rate (the proportion of completely consumed carcasses), (5) consumption time (time elapsed since the carcass was available until it was completely consumed), and (6) carcass selectivity (feeding selections of different carcasses by scavengers).

For the inter-species comparisons of (1) and (3), we used multiple comparisons using $\chi^{2}$ goodness-of-fit tests with Bonferroni correction $(\alpha=0.05)$. We analyzed the intergroup comparisons of (2) and (5) using the Kruskal-Wallis test and the analysis of variance (ANOVA), respectively. In the comparisons, we also performed post hoc power analysis with effect size $\eta^{2}$ (Cohen 2008). For (6), we developed generalized linear mixed models (GLMMs), using the visit frequency of each scavenger feeding on carcasses as the response variable, and the types of carcasses as the categorical explanatory variable. For model development, we used a Poisson distribution with a logarithmic link function and considered the study year as a random factor. We validated the model performance using the Akaike information criterion (AIC), 
and used the percentage of deviance explained to quantify each model's goodness-of-fit; i.e., $\% \mathrm{DE}=(1-$ Deviance/ Null deviance) $\times 100$. We performed all procedures using $\mathrm{R}$ version 3.4.0 (R Development Core Team 2017).

To compare the species richness among scavenger assemblages using different types of carcasses, we drew sample-based rarefaction and extrapolation curves with 100 randomizations (Colwell et al. 2012), using all the sets of scavengers confirmed in each experiment as the reference samples. When drawing extrapolation curves, we predicted the expected species richness and two-sided 95\% confidence intervals (CIs) for up to 20 samples. We conducted this comparison for every site using the software Estimate S 9.1.0 (developed by R. K. Colwell, University of Connecticut, U.S.A.). Based on this simulation, we also validated the sample completeness of each experiment, which is measured by sample coverage-i.e., the proportion of the total number of individuals that belong to the species detected in the sample (Chao and Jost 2012).

\section{Results}

From the current experiments, we confirmed five mediumsized carnivores and seven avian species as scavengers (Table 1). We observed cannibalism; namely, raccoon dogs consumed carcasses of consecifics. While the carcasses of civet, hare, and macaques were completely consumed, the experiments using fresh meat portions of wild boar showed relatively low consumption rates (Table 1). In fact, there were no experiments where any scavengers did not emerge, except for 5 out of 12 experiments using boars. There were meaningful differences in the consumption time among carcass types (ANOVA, $F_{5,32}=2.21, p=0.08$; effect size $\eta^{2}=0.26$ ), and the longest consumption time was observed in carcasses of macaques and raccoon dogs, which were completely consumed within 3-4 weeks.

Among the experiments where carcasses were completely consumed (i.e., 38 out of 50 experiments), martens were consistently high-frequency scavengers that detected carcasses first

Table 1 List of scavengers consuming different vertebrate carcasses and their consumption rate (\%) and time (days) in the heavy-snow condition of northern Japan

\begin{tabular}{|c|c|c|c|c|c|c|}
\hline \multirow[b]{2}{*}{ Scavengers } & \multicolumn{6}{|c|}{ Carcass type } \\
\hline & $\begin{array}{l}\text { Wild } \\
\text { boar (Sus } \\
\text { scrofa) }\end{array}$ & Masked palm civet & $\begin{array}{l}\text { Japanese hare } \\
\text { (Lepus brachyu- } \\
\text { rus) }\end{array}$ & $\begin{array}{l}\text { Japanese macaque } \\
\text { (Macaca fuscata) }\end{array}$ & Raccoon dog & $\begin{array}{l}\text { Domestic chicken } \\
\text { (Gallus gallus } \\
\text { domesticus) }\end{array}$ \\
\hline $\begin{array}{l}\text { Raccoon dog (Nyctereutes pro- } \\
\text { cyonoides) }\end{array}$ & $\checkmark$ & $\checkmark$ & $\checkmark$ & $\checkmark$ & $\checkmark$ & $\checkmark$ \\
\hline $\begin{array}{l}\text { Japanese marten (Martes mela- } \\
\text { mpus) }\end{array}$ & $\checkmark$ & $\checkmark$ & $\checkmark$ & $\checkmark$ & $\checkmark$ & $\checkmark$ \\
\hline Red fox (Vulpes vulpes) & - & $\checkmark$ & $\checkmark$ & $\checkmark$ & $\checkmark$ & $\checkmark$ \\
\hline $\begin{array}{l}\text { Masked palm civet (Paguma } \\
\text { larvata) }\end{array}$ & - & - & - & $\checkmark$ & $\checkmark$ & - \\
\hline Japanese weasel (Mustela itatsi) & - & - & - & - & $\checkmark$ & $\checkmark$ \\
\hline $\begin{array}{l}\text { Eurasian jay (Garrulus } \\
\text { glandarius) }\end{array}$ & - & $\checkmark$ & - & $\checkmark$ & $\checkmark$ & - \\
\hline $\begin{array}{l}\text { Northern goshawk (Accipiter } \\
\text { gentilis) }\end{array}$ & - & - & - & $\checkmark$ & - & - \\
\hline $\begin{array}{l}\text { Jungle crow (Corvus macro- } \\
\text { rhynchos) }\end{array}$ & - & - & $\checkmark$ & $\checkmark$ & $\checkmark$ & - \\
\hline $\begin{array}{l}\text { White-tailed eagle (Haliaeetus } \\
\text { albicilla) }\end{array}$ & - & - & $\checkmark$ & - & - & - \\
\hline Black kite (Milvus migrans) & - & $\checkmark$ & - & - & - & - \\
\hline $\begin{array}{l}\text { Eastern buzzard (Buteo japoni- } \\
\text { cus) }\end{array}$ & - & - & - & $\checkmark$ & - & - \\
\hline $\begin{array}{l}\text { Mountain hawk-eagle (Nisaetus } \\
\text { nipalensis) }\end{array}$ & - & $\checkmark$ & - & - & $\checkmark$ & - \\
\hline$N$ & 12 & 9 & 3 & 5 & 6 & 15 \\
\hline Consumption rate & 33.3 & 100.0 & 100.0 & 100.0 & 66.7 & 86.7 \\
\hline Consumption time $($ mean $\pm \mathrm{SE})$ & $11.6 \pm 8.0$ & $17.4 \pm 4.7$ & $11.3 \pm 5.4$ & $28.0 \pm 5.5$ & $21.1 \pm 4.0$ & $7.3 \pm 2.9$ \\
\hline
\end{tabular}


(20 experiments; $\chi^{2}$ goodness-of-fit test with Bonferroni correction: $p<0.05)$, followed by raccoon dogs (10 experiments). Mean ( \pm standard error, $S E)$ initial detection time of martens and raccoon dogs was $3.67 \pm 1.18$ days and $2.35 \pm 3.90$ days, respectively; cf., that of all scavengers combined was $3.86 \pm 1.08$ days.

The distribution of day/night-time visit frequencies showed that most mammalian scavengers emerged only at night (Fig. 2). Among them, the frequencies of raccoon dogs and martens were significantly higher at night $\left(\chi^{2}\right.$ goodness-of-fit test with Bonferroni correction: $p<0.05)$. Avian scavengers appeared only during the daytime, but their visit frequencies were extremely low compared to mammalian scavengers. In addition, the number of experiments where the avian scavengers visited and consumed carcasses once or more was only 10 out of 50 (i.e., 20\%), which was markedly lower than the number of experiments in which mammalian scavengers visited (43 out of 50, i.e., $86 \%$ ). In contrast, there was no significant difference in the time spent feeding per visit among scavengers (Fig. 3; Kruskal-Wallis test, $\mathrm{df}=4$, $\left.\chi^{2}=4.63, p=0.33, \eta^{2}=0.01\right)$, and every scavenger stayed to consume carcasses for $<10 \mathrm{~min}$ in most cases, except for northern goshawk (Accipiter gentilis), which continued to stay for a relatively prolonged time (median $=24 \mathrm{~min}$ ). Subsequently, we attempted to construct GLMMs for evaluating carcass selections by the top 3 scavengers frequently emerging (i.e., raccoon dog, Japanese marten, and red fox; Fig. 2) and all species combined. We succeeded in acquiring predictive models for raccoon dogs ( $\mathrm{AIC}=114.8 ; \% \mathrm{DE}=20.6$ ) and all species combined ( $\mathrm{AIC}=135.6 ; \% \mathrm{DE}=44.2)$. Both models indicated that the carcasses of macaques and raccoon dogs were positively selected as attractive resources (Fig. 4).

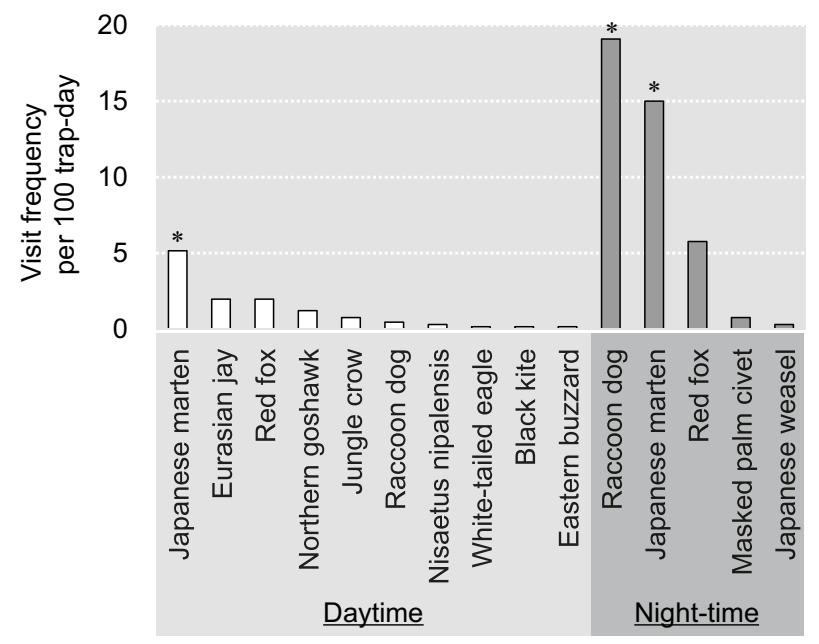

Fig. 2 Day- and night-time frequency of scavengers emerging to consume carcasses in heavy snow conditions, northern Japan. Sampling efforts were 660 trap-days for both daytime and night-time. Asterisks show the significantly high visit frequency during the daytime or night-time ( $\chi^{2}$ goodness-of-fit tests with Bonferroni corrections; $\alpha=0.05)$

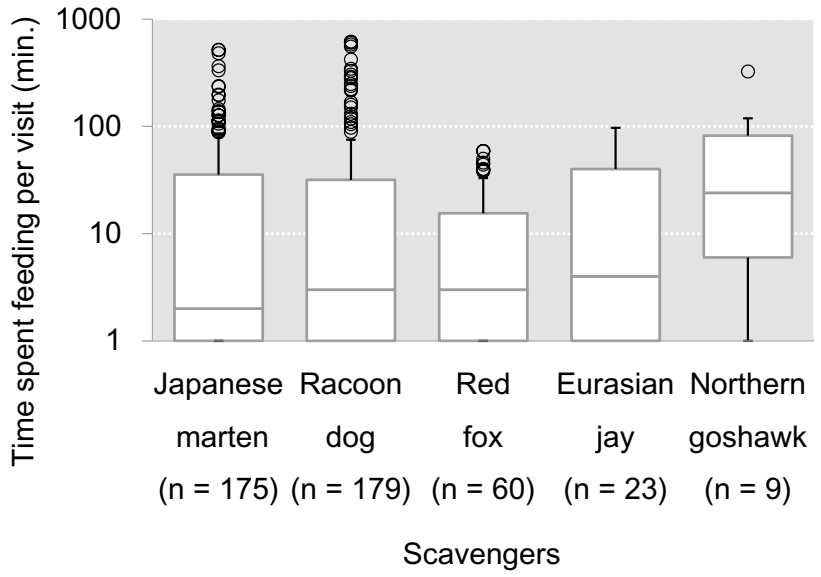

Fig. 3 Boxplots showing time spent feeding for each scavenger species. The line in the middle of the box represents the median, and the lower and upper ends of the box are the 25 and $75 \%$ quartiles, respectively. The lines indicate 1.5 times the size of the hinge, which is the 75 minus $25 \%$ quartiles. Points beyond these lines are outliers

In contrast, no significant explanatory variables were confirmed in the models for Japanese martens and red foxes, indicating that these two could be euryphagous scavengers.

The sample completeness according to the rarefaction and extrapolation curves (Fig. 5) was estimated at $100.0 \%$ for wild boar, $82.3 \%$ for civet, $76.9 \%$ for hare, $89.7 \%$ for

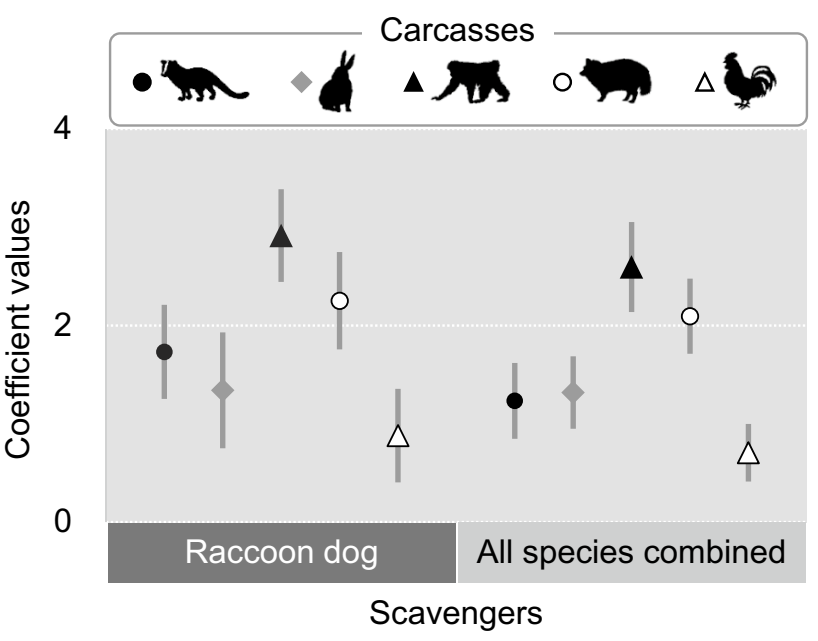

Fig. 4 Mean \pm SE of explanatory variables in each generalized linear mixed model to estimate feeding selections of 6 different carcasses (i.e., wild boar, masked palm civet, Japanese hare, Japanese macaque, raccoon dog, and domestic chicken) by raccoon dog (i.e., the species most frequently emerging) and all vertebrate scavengers combined, in heavy snow conditions of northern Japan. We assigned boar carcasses to a reference for the categorical variable. Every coefficient showed $\operatorname{Pr}(z)<0.05$. Survey efforts (total trap-day) were 92.7 for wild boar, 156.9 for masked palm civet, 34.0 for Japanese hare, 140.2 for Japanese macaque, 130.0 for raccoon dog, and 106.3 for domestic chicken 


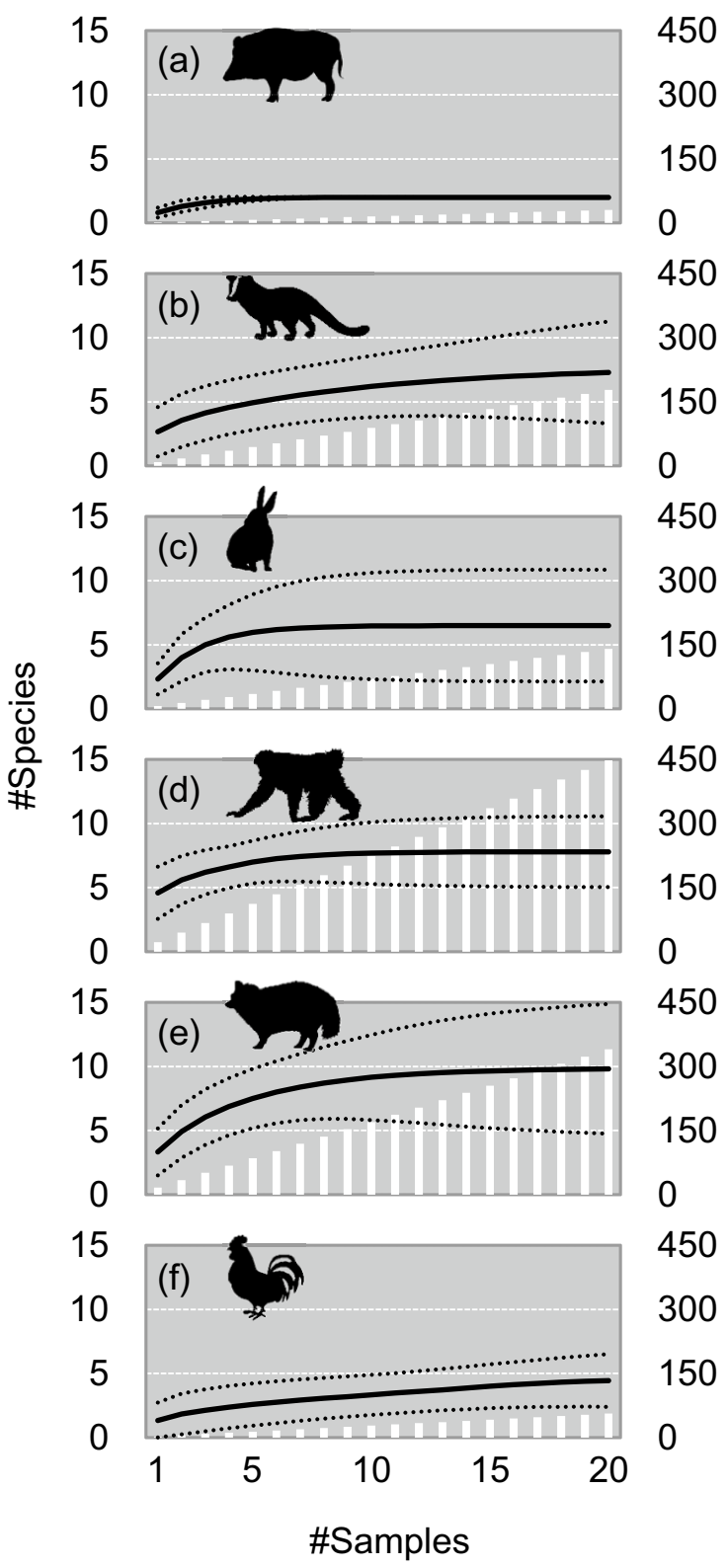

Fig. 5 Expected species richness of vertebrate scavengers using 6 different carcasses (broken lines) and expected event counts that they emerged to consume carcasses (bars) in heavy snow areas of northern Japan, estimated by rarefaction and extrapolation curves. The $x$-axis (i.e., \#Samples) shows the repetition number of experiments. As for the line graphs, solid and dashed lines show expected values and $95 \%$ confidence intervals, respectively

macaque, $81.6 \%$ for raccoon dog, and $89.9 \%$ for chicken. This indicates that the current sampling efforts to verify the scavenger richness were appropriate. The simulations also demonstrated that, while the attractiveness of the fresh meat portions of boar and chicken was limited for most scavengers, the diversity and visit frequency were relatively high for the full-body carcasses (i.e., civet, hare, macaque, and raccoon dog).

\section{Discussion}

\section{Carcass consumption rates}

According to a systematic review regarding the inventory of scavengers using hunting remains (Mateo-Tomás et al. 2015), up to 79 vertebrate species have been reported as scavengers worldwide. Under ecosystems with obligate scavengers (i.e., vultures), carcasses are expected to be more efficiently consumed and, in fact, the mean carcass decomposition rates are three (Ogada et al. 2012) to ten (Hill et al. 2018) times higher than those in an ecosystem without obligate scavengers. Although vultures are absent in the current study area, the mean consumption rate for all the experiments $(n=50)$ reached nearly $80 \%$. The mean for the experiments using the full-body carcasses $(n=28)$ was even higher, i.e., $91.3 \%(n=23)$ (Table 1). The current study could not elucidate the reasons for these high consumption rates, but it is reasonable to hypothesize that the depletion of readily available food resources due to heavy snowfall causes dependence on carcasses buried in snow, as it is one of the few predicable resources for mammalian scavengers in winter. Moreover, considering that frozen carcasses are hardly consumed by scavengers (Selva et al. 2003), the presence of heavy snowfall might also explain this high consumption rate, since piled snow could protect carcasses from the freezing air.

In contrast, the consumption rates for the fresh meat portions of wild boars were relatively low (Table 1). This could explain the possibility that the presence of full-body carcasses, especially including intestines-which include various specific microbes contributing the decay process of carcasses and emitting putrefactive odor (Dent et al. 2004) - are crucially important in enhancing the detectability of snow-buried carcasses by scavengers. Even in the presence of microbes in the intestine, the decay process is not very distinct under freezing conditions. However, the cover of snow piles could protect carcasses from the freezing air, and therefore, the decay process triggered by the microbes would not stop completely. Thus, carcasses with intestines could still provide some odor cues in winter for vertebrate scavengers. In future studies, the validity of this putrefaction hypothesis should be tested with additional experiments to reveal the detailed decay processes of carcasses buried under snow and the detection rates by mammalian scavengers of carcasses in different states of decay from fresh to rotten. 


\section{Who is the most efficient scavenger under heavy snow conditions?}

According to a systematic review by Mateo-Tomás et al. (2015), vertebrate scavenger richness varies among biomes (6-29 species) and is positively correlated with the total number of vertebrate species observed in the respective biomes. Extreme biomes, such as arid and tundra regions, tend to have a vulnerable scavenger richness, which is two to three times lower than other biomes (Mateo-Tomás et al. 2015). Our study area, characterized by extremely heavy snowfall, supported this trend; the total scavenger richness was relatively low with only 12 species. We observed avian scavengers here (i.e., 7 species), but their visits were extremely infrequent compared with those of nocturnal mammalian scavengers, namely, raccoon dogs and martens (Fig. 2), which were able to detect carcasses more quickly and frequently. Notably, even during nonsnowy seasons, the visit frequency of avian scavengers is originally limited in cool-temperate forests of Japan where dense vegetation with a closed canopy is common. In fact, Inagaki et al. (2020) reported that less than half of sika deer carcasses were consumed by avian scavengers during the summer (i.e., $40.0 \%, n=20)$ and fall $(45.5 \%, n=22)$. Although canopy openness improves during winter due to defoliation, the current experiments showed even lower values (i.e., 20\%). In many biomes, the trophic interactions show an opposite trend; that is, avian scavengers are superior to mammals in terms of scavenging frequency (Selva et al. 2003; Mateo-Tomás et al. 2015). The current finding is relevant to the following well-known fact. Although the olfaction of avian species has been considered a functional sense in various ethological contexts (Steiger et al. 2008; Balthazart and Taziaux 2009), avian scavengers are compelled to solely depend on visual cues when locating carcasses in a wider area from the sky (Houston 1988; DeVault and Rhodes 2002; Selva et al. 2003), excluding some obligate scavengers (i.e., vultures) with a highly developed olfactory sense (Lisney et al. 2013). Hence, it is quite likely that the avian scavengers would have difficulties accessing the carcasses masked by snow. A partly related phenomenon has been observed in temperate forests with mild winters, i.e., Białowieża Forest, Poland, where the maximum snow depth is $<40 \mathrm{~cm}$ (Selva et al. 2005). This previous study reported that visual masking effects of snowfall are applicable only for large avian scavengers but not for small ones such as jays (Garrulus glandarius). The current study indicates that more powerful masking effects were elicited for every avian species, including small ones, due to massive snowfall (Fig. 2). However, if avian scavengers can subsequently detect resources possibly by using clues on the snow surface left by mammalian scavengers such as tracks and digging, they are likely to hold doggedly onto resources. This notion could be supported by the fact that, although the time spent feeding per visit by avian species is less than half of that of mammals during non-snowy seasons (Inagaki et al. 2020), the current findings exactly showed an opposite trend (Fig. 3).

Unlike live prey, carcasses are unpredictable resources (DeVault et al. 2003). The only way to improve the detection rate of carcasses is to search wider areas using olfactory cues, which are limited by snow cover. Even without snow, however, the detection range of terrestrial scavengers using visual sense is often subject to the restriction of dense vegetation and topographical relief (Kane et al. 2017). Hence, most terrestrial carnivores are accustomed to using their superior olfactory sense, the detection range of which generally exceeds $500 \mathrm{~m}$ (Kane et al. 2017), i.e., the capacity required for surviving as a scavenger (Ruxton and Houston 2004). Although the actual detection capability of carcasses buried under snow should be measured in the future, the current findings show that the mesocarnivores observed had sufficient olfactory information to surmount the masking effect of a $>30-\mathrm{cm}$ layer of snow and become the only prominent scavengers in heavy snow ecosystems lacking large carnivores, i.e., wolves (human-induced extinction) and black bears (hibernation).

During non-snowy seasons, black bears are expected to join the scavenger guild as a dominant player in cool-temperate forests (Inagaki et al. 2020), presumably including our study area. Black bears potentially have a greater impact on regional scavenger communities by monopolizing most available carcasses (Allen et al. 2014, 2015). Although we should refrain from discussing the influence of the presence/ absence of black bears on scavenger communities due to the lack of year-round carcass monitoring in the study area, we would like to highlight that no significant changes in feeding behaviors of the leading scavengers (i.e., raccoon dogs and martens), such as an increase in visit frequency and time spent feeding during winters, were observed, at least compared to the results of Inagaki et al. (2020). This might be because, instead of being relieved of severe competition with black bears during winters, the mesocarnivores were compelled to face an increase in thermoregulatory costs and movement costs stemming from cold and snow, which strictly restrict their activity budgets, as is obviously shown in co-occurring mammals (e.g., Japanese macaque; Enari 2014).

\section{Selectivity of carcass types by scavengers}

It has been widely observed that a difference in carcass size influences the consumption process (Moleón et al. 2015; Kane et al. 2017); for example, an increase in carcass size enhances the species richness of vertebrate scavengers 
(Mateo-Tomás et al. 2015; Turner et al. 2017) and causes variation in the selectivity of carcass types by scavengers, often resulting in increased consumption efficiency (Moleón et al. 2015). This general trend could be distinctly demonstrated in heavy snow ecosystems; both the species richness of scavenger assemblages and the frequency of carcass consumption were the highest for macaques, the largest carcasses used in our experiments (Fig. 5). Although macaques are one of the few primate species that can cope with cold and snow, their mortality rate is highest in winter (Enari 2014). Considering that the relative abundance of macaques was $>10$ times greater than that of the dominant scavengers in the current study area (i.e., raccoon dogs and martens; see Study area), macaques could be important resources to sustain the scavenger guild.

Regarding carcass selection, we should also draw attention to feeding behavior to consume carnivores' carcasses and moreover, cannibalism frequently observed in the current study (Fig. 4). In general, possibly to lower the parasitebased mortality rates, vertebrate scavengers tend to avoid consuming the carcasses of carnivores, especially conspecifics (DeVault et al. 2003; Selva et al. 2005; Olson et al. 2016; Moleón et al. 2017). Based on statistical simulations using an agent-based model, however, Moleón et al. (2017) demonstrated that carnivore scavenging at the inter- or intraspecific level occurs when the pathogenicity of parasites is low, and a concomitant risk of starvation exists, due to an insufficient availability of herbivore carcasses. If we stick to this model, the carnivore scavenging, including cannibalism, observed here might become understandable, because (1) cold climates may contribute toward inhibiting the growth of pathogenic parasites, and (2) large-sized herbivores in the current study area (i.e., sika deer and wild boar) became extinct over a century ago

\section{Concluding remarks}

Heavy snowfall conditions undoubtedly ensure a supply of available carcasses for mammalian scavengers in winter by increasing the mortality rate of many non-hibernating mammals. As suggested by Selva and Fortuna (2007), facultative scavenging in such harsh environments may not be random and opportunistic, but possibly becomes systematically integrated into the foraging tactics of many mammalian scavengers. This theory was empirically supported by the extremely high carcass consumption rates in areas where only limited odor cues are effective. The carcass detection time observed in the current study (approximately $90 \mathrm{~h}$ ) also compares favorably with that in other ecosystems without snow, if obligate scavengers are absent (in southeastern Spain, $64 \mathrm{~h}$ and $88 \mathrm{~h}$ carcass detection time was observed for herbivore and carnivore carcasses, respectively, during winters; Moleón et al. 2017).

The current experiments were conducted only during midwinter with heavy snowfall. In the time after this period, i.e., during the snow-melting season, the decomposition process might markedly change because the limitation of visual cues disappears, implying that avian scavengers can participate more actively in the carcass consumption process. Moreover, the possible dominant scavengers, black bears, would emerge from hibernation (Mizukami et al. 2005; Huang et al. 2014). Such meteorological and phenological transitions would certainly change the scavenger assemblages and trophic networks inherent in heavy snow regions.

Acknowledgements We thank Kengo Ito, Reina Onodera-Uno, and Tatsuhito Sekiguchi for collecting fresh carcasses. We also thank Marcus Clauss and the anonymous reviewers for providing useful suggestions to improve our manuscript. All research reported in this paper adhered strictly to the current laws of Japan.

Funding This work was supported by JSPS KAKENHI grant number 23710279, 26701007, and 20K06089 to H. E.

Data availability The datasets generated during the current study are available from the corresponding author on reasonable request.

\section{Compliance with ethical standards}

Conflict of interest The authors declare that they have no conflict of interest.

Open Access This article is licensed under a Creative Commons Attribution 4.0 International License, which permits use, sharing, adaptation, distribution and reproduction in any medium or format, as long as you give appropriate credit to the original author(s) and the source, provide a link to the Creative Commons licence, and indicate if changes were made. The images or other third party material in this article are included in the article's Creative Commons licence, unless indicated otherwise in a credit line to the material. If material is not included in the article's Creative Commons licence and your intended use is not permitted by statutory regulation or exceeds the permitted use, you will need to obtain permission directly from the copyright holder. To view a copy of this licence, visit http://creativecommons.org/licenses/by/4.0/.

\section{References}

Allen ML, Elbroch LM, Wilmers CC, Wittmer HU (2014) Trophic facilitation or limitation? Comparative effects of pumas and black bears on the scavenger community. PLoS ONE 9:e102257. https ://doi.org/10.1371/journal.pone.0102257

Allen ML, Elbroch LM, Wilmers CC, Wittmer HU (2015) The comparative effects of large carnivores on the acquisition of carrion by scavengers. Am Nat 185:822-833. https://doi.org/10.1086/681004

Balthazart J, Taziaux M (2009) The underestimated role of olfaction in avian reproduction? Behav Brain Res 200:248-259. https://doi. org/10.1016/j.bbr.2008.08.036

Beasley JC, Olson ZH, DeVault TL (2015) Ecological role of vertebrate scavengers. In: Benbow M, Tomberlin J, Tarone A (eds) Carrion 
ecology, evolution and their applications. CRC Press, Boca Raton, pp 107-127

Beasley JC, Olson ZH, Selva N, DeVault TL (2019) Ecological functions of vertebrate scavenging. In: Olea PP, Mateo-Tomás P, Zapata S, Antonio J (eds) Carrion ecology and management. Springer, Cham, Switzerland, pp 125-157

Chao A, Jost L (2012) Coverage-based rarefaction and extrapolation: standardizing samples by completeness rather than size. Ecology 93:2533-2547. https://doi.org/10.1890/11-1952.1

Cohen BH (2008) Explaining psychological statistics, 3rd edn. Wiley, New Jersey

Colwell RK, Chao A, Gotelli NJ, Lin S-Y, Mao CX, Chazdon RL, Longino JT (2012) Models and estimators linking individualbased and sample-based rarefaction, extrapolation and comparison of assemblages. J Plant Ecol 5:3-21. https://doi.org/10.1093/ jpe/rtr044

Dent BB, Forbes SL, Stuart BH (2004) Review of human decomposition processes in soil. Environ Geol 45:576-585. https://doi. org/10.1007/s00254-003-0913-z

DeVault TL, Rhodes OE Jr, Shivik JA (2003) Scavenging by vertebrates: behavioral, ecological, and evolutionary perspectives on an important energy transfer pathway in terrestrial ecosystems. Oikos 102:225-234. https://doi.org/10.1034/j.1600-0706.2003.12378.x

DeVault TL, Rhodes OE (2002) Identification of vertebrate scavengers of small mammal carcasses in a forested landscape. Acta Theriol 47:185-192. https://doi.org/10.1007/BF03192458

Enari H (2014) Snow tolerance of Japanese macaques inhabiting highlatitude mountainous forests of Japan. In: Grow N, Gursky-Doyen S, Krzton A (eds) High altitude primates. Springer, New York, pp 133-151. https://doi.org/10.1007/978-1-4614-8175-1_8

Hill JE, DeVault TL, Beasley JC, Rhodes OE Jr, Belant JL (2018) Effects of vulture exclusion on carrion consumption by facultative scavengers. Ecol Evol 8:2518-2526. https://doi.org/10.1002/ ece 3.3840

Houston DC (1988) Competition for food between Neotropical vultures in forest. IBIS 130:402-417. https://doi.org/10.1111/j.1474919X.1988.tb08815.x

Huang Z-P, Qi X-G, Garber PA, Jin T, Guo S-T, Li S, Li B-G (2014) The use of camera traps to identify the set of scavengers preying on the carcass of a golden snub-nosed monkey (Rhinopithecus roxellana). PLoS ONE 9:e87318. https://doi.org/10.1371/journ al.pone. 0087318

Huggard DJ (1993) Effect of snow depth on predation and scavenging by gray wolves. J Wildl Manage 57:382-388. https://doi. org $/ 10.2307 / 3809437$

Inagaki A, Allen ML, Maruyama T, Yamazaki K, Tochigi K, Naganuma T, Koike S (2020) Vertebrate scavenger guild composition and utilization of carrion in an East Asian temperate forest. Ecol Evol 10:1223-1232. https://doi.org/10.1002/ece3.5976

Kane A, Healy K, Guillerme T, Ruxton GD, Jackson AL (2017) A recipe for scavenging in vertebrates-the natural history of a behaviour. Ecography 40:324-334. https://doi.org/10.1111/ecog.02817

Koganezawa M (1991) The effect of severe winter on natality of Japanese monkeys in Nikko. In: Ehara A, Kimura T, Takenaka O, Iwamoto M (eds) Primatology Today. Elsevier Science Publishers, Amsterdam, pp 129-130

Lisney TJ, Stecyk K, Kolominsky J, Graves GR, Wylie DR, Iwaniuk AN (2013) Comparison of eye morphology and retinal topography in two species of new world vultures (Aves: Cathartidae). Anat Rec 296:1954-1970. https://doi.org/10.1002/ar.22815

Mateo-Tomás P, Olea PP, Moleón M, Selva N, Sánchez-Zapata JA (2017) Both rare and common species support ecosystem services in scavenger communities. Global Ecol Biogeogr 26:1459-1470. https://doi.org/10.1111/geb.12673
Mateo-Tomás P et al (2015) From regional to global patterns in vertebrate scavenger communities subsidized by big game hunting. Divers Distrib 21:913-924. https://doi.org/10.1111/ddi.12330

Mizukami RN, Goto M, Izumiyama S, Hayashi H, Yoh M (2005) Estimation of feeding history by measuring carbon and nitrogen stable isotope ratios in hair of Asiatic black bears. Ursus 16:93-101. https://doi.org/10.2192/1537-6176(2005)016[0093:EOFHB $\mathrm{M}] 2.0 . \mathrm{CO} ; 2$

Moleón M, Martinez-Carrasco C, Muellerklein OC, Getz WM, MuñozLozano C, Sánchez-Zapata JA (2017) Carnivore carcasses are avoided by carnivores. J Anim Ecol 86:1179-1191. https://doi. org/10.1111/1365-2656.12714

Moleón M, Sánchez-Zapata JA, Margalida A, Carrete M, Owen-Smith N, Donázar JA (2014) Humans and scavengers: the evolution of interactions and ecosystem services. Bioscience 64:394-403. https ://doi.org/10.1093/biosci/biu034

Moleón M, Sánchez-Zapata JA, Sebastián-González E, Owen-Smith $\mathrm{N}$ (2015) Carcass size shapes the structure and functioning of an African scavenging assemblage. Oikos 124:1391-1403. https:// doi.org/10.1111/oik.02222

Ochiai K, Nakama S, Hanawa S, Amagasa T (1993) Population dynamics of Japanese serow in relation to social organization and habitat conditions. I. Stability of Japanese serow density in stable habitat conditions. Ecol Res 8:11-18. https://doi. org/10.1007/BF02348602

Ogada D, Torchin M, Kinnaird M, Ezenwa V (2012) Effects of vulture declines on facultative scavengers and potential implications for mammalian disease transmission. Conserv Biol 26:453-460. https://doi.org/10.1111/j.1523-1739.2012.01827.x

Olson ZH, Beasley JC, Rhodes OE Jr (2016) Carcass type affects local scavenger guilds more than habitat connectivity. PLoS ONE 11:e0147798. https://doi.org/10.1371/journal.pone.01477 98

R Development Core Team (2017) R: A language and environment for statistical computing.

Ruxton GD, Houston DC (2004) Obligate vertebrate scavengers must be large soaring fliers. J Theor Biol 228:431-436. https://doi. org/10.1016/j.jtbi.2004.02.005

Sebastián-González E et al (2019) Scavenging in the Anthropocene: Human impact drives vertebrate scavenger species richness at a global scale. Global Change Biol 25:3005-3017. https://doi. org/10.1111/gcb.14708

Sebastián-González E et al (2020) Network structure of vertebrate scavenger assemblages at the global scale: drivers and ecosystem functioning implications. Ecography 43:1143-1155. https://doi. org/10.1111/ecog.05083

Selva N, Fortuna MA (2007) The nested structure of a scavenger community. Proc R Soc Lond B Biol Sci 274:1101-1108. https://doi. org/10.1098/rspb.2006.0232

Selva N, Jedrzejewska B, Jedrzejewski W, Wajrak A (2003) Scavenging on European bison carcasses in Bialowieza Primeval Forest (eastern Poland). Ecoscience 10:303-311. https://doi. org/10.1080/11956860.2003.11682778

Selva N, Jędrzejewska B, Jędrzejewski W, Wajrak A (2005) Factors affecting carcass use by a guild of scavengers in European temperate woodland. Can J Zool 83:1590-1601. https://doi.org/10.1139/ z05-158

Smith JB, Laatsch LJ, Beasley JC (2017) Spatial complexity of carcass location influences vertebrate scavenger efficiency and species composition. Sci Rep 7:10250. https://doi.org/10.1038/s4159 8-017-10046-1

Steiger SS, Fidler AE, Valcu M, Kempenaers B (2008) Avian olfactory receptor gene repertoires: evidence for a well-developed sense of smell in birds? Proc R Soc Lond B Biol Sci 275:2309-2317. https ://doi.org/10.1098/rspb.2008.0607 
Sugiura S, Hayashi M (2018) Functional compensation by insular scavengers: the relative contributions of vertebrates and invertebrates vary among islands. Ecography 41:1173-1183. https://doi. org/10.1111/ecog.03226

Sugiura S, Tanaka R, Taki H, Kanzaki N (2013) Differential responses of scavenging arthropods and vertebrates to forest loss maintain ecosystem function in a heterogeneous landscape. Biol Conserv 159:206-213. https://doi.org/10.1016/j.biocon.2012.11.003

Takatsuki S, Suzuki K, Suzuki I (1994) A mass-mortality of sika deer on Kinkazan Island, northern Japan. Ecol Res 9:215-223. https:// doi.org/10.1007/BF02347497

Tsunoda H, Enari H (2012) Ecological role and social significance of reintroducing wolves in Japan under the shrinking society. In: Maia A, Crussi H (eds) Wolves: biology, behavior and conservation. Nova Science, New York, pp 177-198

Turner KL, Abernethy EF, Conner LM, Rhodes OE Jr, Beasley JC (2017) Abiotic and biotic factors modulate carrion fate and vertebrate scavenging communities. Ecology 98:2413-2424. https:// doi.org/10.1002/ecy.1930
Wilman H, Belmaker J, Simpson J, de la Rosa C, Rivadeneira MM, Jetz W (2014) EltonTraits 1.0: species-level foraging attributes of the world's birds and mammals. Ecology 95:2027-2027. https://doi. org/10.1890/13-1917.1

Wilmers CC, Crabtree RL, Smith DW, Murphy KM, Getz WM (2003) Trophic facilitation by introduced top predators: grey wolf subsidies to scavengers in Yellowstone National Park. J Anim Ecol 72:909-916. https://doi.org/10.1046/j.1365-2656.2003.00766.x

Wilson EE, Wolkovich EM (2011) Scavenging: how carnivores and carrion structure communities. Trends Ecol Evol 26:129-135. https://doi.org/10.1016/j.tree.2010.12.011

Publisher's Note Springer Nature remains neutral with regard to jurisdictional claims in published maps and institutional affiliations. 